\section{Pacific Northwest}

National Laboratory

Operated by Battelle for the

U.S. Department of Energy

\title{
Beyond Commissioning: The Role of Automation
}

\author{
MR Brambley \\ S Katipamula
}

February 2005

Prepared for the U.S. Department of Energy under Contract DE-AC05-76RL01830 


\title{
DISCLAIMER
}

This report was prepared as an account of work sponsored by an agency of the United States Government. Neither the United States Government nor any agency thereof, nor Battelle Memorial Institute, nor any of their employees, makes any warranty, express or implied, or assumes any legal liability or responsibility for the accuracy, completeness, or usefulness of any information, apparatus, product, or process disclosed, or represents that its use would not infringe privately owned rights. Reference herein to any specific commercial product, process, or service by trade name, trademark, manufacturer, or otherwise does not necessarily constitute or imply its endorsement, recommendation, or favoring by the United States Government or any agency thereof, or Battelle Memorial Institute. The views and opinions of authors expressed herein do not necessarily state or reflect those of the United States Government or any agency thereof.

\author{
PACIFIC NORTHWEST NATIONAL LABORATORY \\ operated by \\ BATTELLE \\ for the \\ UNITED STATES DEPARTMENT OF ENERGY \\ under Contract DE-AC05-76RL01830
}

Printed in the United States of America
Available to DOE and DOE contractors from the Office of Scientific and Technical Information,
P.O. Box 62, Oak Ridge, TN 37831-0062;
ph: (865) 576-8401
fax: $(865)$ 576-5728
email: reports@adonis.osti.gov

\begin{abstract}
Available to the public from the National Technical Information Service, U.S. Department of Commerce, 5285 Port Royal Rd., Springfield, VA 22161 ph: (800) 553-6847 fax: $(703) 605-6900$ email: orders@ntis.fedworld.gov online ordering: http://www.ntis.gov/ordering.htm
\end{abstract}

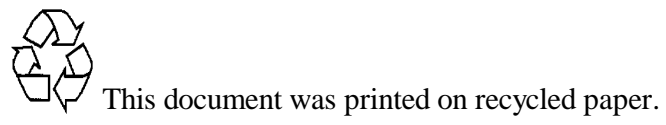


February 2005

Article

AutomatedBuildings.com

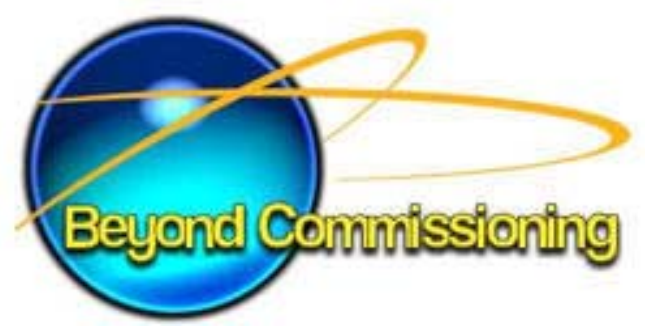

Dealers Wanted For Web Based Building

Automation System

Computrols, Inc.

(Click Message to Learn More)

\section{Michael R. Brambley and Srinivas Katipamula \\ Pacific Northwest National Laboratory ${ }^{2}$}

The Role of Automation ${ }^{1}$

Michael Brambley manages the Building Systems Program at Pacific Northwest National Laboratory (PNNL), where his work focuses on developing and deploying technology to increase the energy efficiency of buildings and other energy using systems. His primary research thrusts in recent years have been in development and application of automated fault detection and diagnostics and wireless sensing and control. He has been

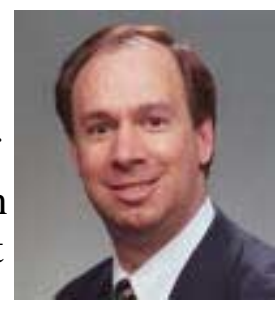
with PNNL for 17 years before which he was an Assistant Professor in the Engineering School at Washington University in St. Louis. He holds M.S. (1978) and Ph.D. (1981) degrees from the University of California, San Diego, and the B.S. (1976) from the University of Pennsylvania, and is the author of more than 60 technical publications and numerous research project reports. He is an active member of the American Society of Heating, Refrigerating, and Air-Conditioning Engineers (ASHRAE) for which he has served on technical committees for Computer Applications and Smart Building Systems. Michael has been the organizer of numerous seminars and symposia at ASHRAE's semiannual meetings and is a member of ASHRAE's Program Committee. In addition to several other professional organizations, Michael is a member of the Instrumentation, Systems, and Automation Society (ISA) and Sigma Xi, The Scientific Research Society.

Srinivas Katipamula received his M.S. and Ph.D. in Mechanical Engineering in 1985 and 1989, respectively, from Texas A\&M University. He has been working as a Sr. Research Scientist at Pacific Northwest National Laboratory (PNNL), in Richland, WA, since January 2002. For two years (2000 through 2001) he managed the Analytics Group at the Enron Energy Services (EES). Before joining EES, he worked at PNNL for 6 years and prior to that he worked for the Energy

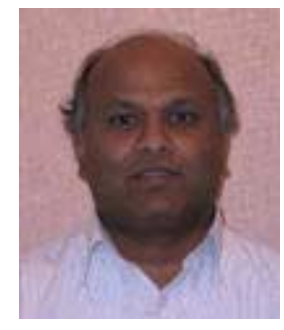
Systems Lab at the Texas A\&M University from 1989 to 1994. He has authored or coauthored over 60 technical publications, over 40 research reports, and made several presentations at national and international conferences. He is an active member of both American Society of Heating, Refrigeration, and Air Conditioning Engineers and the American Society of Mechanical Engineers. 


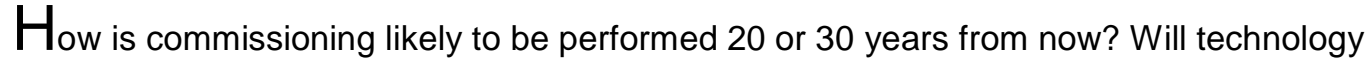
advance to the state where building systems and equipment are automatically commissioned on an on-going basis as conditions demand? The authors of this article believe it will and that the technologies that appear on the pages of Automated Buildings every month - wireless communication, automated diagnostics, advanced controls-are the seeds for the technology that will provide these capabilities.

This article takes a brief look at the benefits of commissioning and describes a vision of the future where most of the objectives of commissioning will be accomplished automatically by capabilities built into the building systems themselves. Commissioning will become an activity that's performed continuously rather than periodically, and only repairs requiring replacement or overhaul of equipment will require manual intervention. The article then identifies some of the technologies that will be needed to realize this vision and ends with a call for all involved in the enterprise of building commissioning and automation to embrace and dedicate themselves to a future of automated commissioning.

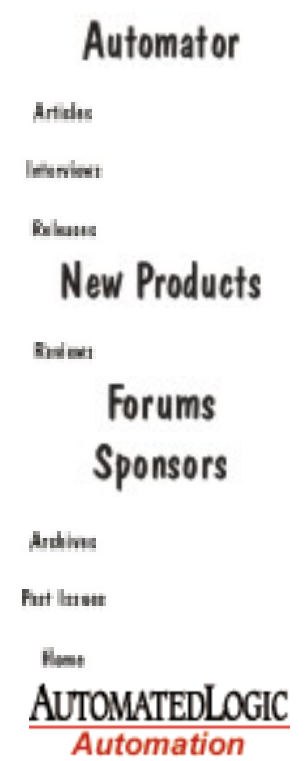

\section{The Value of Commissioning}

Retro-commissioning of existing buildings reduces energy use by anywhere from a few percent to over $60 \%$ of pre-retrocommissioning consumption, with most savings falling into the range of $10 \%$ to $30 \%$ (U.S. DOE undated; Haasl and Sharp 1999; Claridge et al. 2000; and Liu et al. 2002). These savings result from detecting and correcting problems such as:

- incorrectly installed equipment (e.g., backwards fans)

- incorrectly implemented control algorithms (e.g., economizing cycles)

- inefficient set points

- unexpected equipment and lighting schedules that waste energy

- missing, failed and uncalibrated sensors.

Energy savings are more difficult to establish for new construction, but by using building simulation, the savings associated with commissioning can be estimated. A recently published meta-analysis (Mills et al. 2004) found median cost savings on energy of $15 \%$ and payback periods of 0.7 years for retrocommissioning of existing buildings. For commissioning of new buildings, the study found a median payback period of 4.8 years.

While these savings are impressive, penetration of commissioning ${ }^{3}$ in the buildings market remains small. A recent report (Quantum Consulting 2003, pp. 1-3) on commissioning in public buildings states "While the concept of commissioning is increasingly accepted, there are still barriers--particularly with regard to cost--to implementation of the kind of thorough, independent third-party commissioning that is necessary for the full benefits of commissioning to be realized." Only a small fraction of new construction and a very small fraction of existing buildings have been commissioned. Even when performed, pressures exist to keep costs down, which in some cases limits the thoroughness to which the commissioning is performed. The two factors that likely play the most significant roles in limiting the widespread adoption of commissioning and retro-commissioning are: 1) lack of knowledge of the benefits of 
commissioning by key decision makers and 2) the cost of commissioning. This paper focuses on how the costs of commissioning could be lowered substantially by automating the commissioning processes. Fortunately, reducing cost also reduces barriers in decision making, making acceptance by decision makers easier even in the absence of information. Changes to how commissioning is executed that reduce its cost and make it a routine part of how building systems are designed, installed, and operated could in the long run better promote the objectives of commissioning than keeping it a distinct practice. Key to this is reducing the labor intensity of commissioning by automating as many of the processes involved as possible. Compared to the cost of labor, automation technology is inexpensive.

\section{Hypothesis - There's a Better Way}

Commissioning provides important benefits to both new and existing buildings, but there may be a better way to achieve these benefits. In the long-term future (say 20 or 30 years from now), most (but not all) of the objectives of commissioning could be provided using automated processes, reducing many of the barriers that exist today for commissioning and impacting a much larger portion of the building stock. Furthermore, doing so could increase consistency in the commissioning process, improve the reliability of building systems, and make the process of assessing performance, which is a critical part of retro-commissioning, a truly continuous process.

How might this be done? First, identify processes that produce the desired outcomes that could be done automatically. Then develop building equipment, systems, control systems, and tools that implement these processes automatically. Gaps between the automated processes could be filled by manual procedures, ensuring that the activities that absolutely require human intervention and tie the automated processes together are executed efficiently and cost effectively.

In the next two sections, we first provide a vision for commissioning in the distant future after the automated processes are fully developed and implemented, then take a critical look at commissioning to identify the processes that require direct human involvement and processes that do not and could be automated. We then identify technologies that are key to realizing the automated processes and conclude by identifying research and development that will be essential to accomplishing our vision for commissioning of the future.

In doing this, we are not suggesting that commissioning and efforts to promote it be suddenly terminated today. On the contrary, we believe that commissioning as conducted today is important as a transition process. It provides important benefits, but as with most things, it needs improvement over time. Our vision is for the long term. It will not be realized tomorrow, but the vision can help guide $R \& D$ and product development decisions so they lead us to a future where the benefits of commissioning permeate the entire building enterprise. Likewise, as this technology and tools embodying it emerge, commissioning should adapt and change to assimilate these new capabilities, making the commissioning process faster, less expensive, more thorough, more consistent, more reliable, more cost effective, more continuous, and appealing to more of the market. 


\section{Commissioning for the Future-Highly Automated and Efficient}

When operation of a new building or new piece of equipment or system is started in the future, with the push of a "start" button, equipment and systems should all test themselves, identify any installation or configuration problems, automatically fix problems amenable to "soft" solutions, and report the need for "hard" solutions requiring replacement or installation of hardware. A report on the performance of all building systems and equipment should be automatically generated, delivered to key recipients, and stored electronically for future reference and updating. During initial operation (e.g., for the first year) and continuing over its lifetime, the system should optimize itself, integrating its behavior with external constraints, such as occupancy, occupant behavior and feedback, energy prices, demand charges, and weather. Although most of the optimization should take place during this initial period of say a year, the building systems should continue to optimize themselves as prices change, spaces are converted to different AUTOMATEDLOGIC uses, tenants change, and building equipment itself ages and wears. Using prognostics, systems should automatically inform building staff regarding expected lives and recommended service times for equipment. Diagnostics should detect degradation and failure, make "soft" fixes when possible (alerting building staff to changes made and electronically documenting changes automatically made for future reference) and alert staff to performance degradation, impending failures and required maintenance to prevent them.

Realization of this vision will present unique technological challenges, but methods under development (some examples of which are provided in the next section) are addressing these differences. Technology will evolve over time and change the practice of commissioning, bringing benefits to building owners and occupants. Ours is a vision for buildings of the future that automatically will perform many of the actions required to meet the objectives of commissioning, where technology will provide the cornerstone for achieving this future.

\section{What Parts of Commissioning Could be Automated?}

The major tasks composing commissioning of new buildings and retro-commissioning of existing buildings are shown in Table 1 by phase of the project. Some processes are critical to accomplishing the objectives of commissioning. Other processes exist to support commissioning specifically as it is performed today. If the overall process of commissioning were changed, some of these processes might become unnecessary or would be modified considerably. The same overall objectives might be achieved without an identical set of processes. Table 1 includes designations of whether activities would be manual $(M)$ or automated $(A)$ in a highly automated future for commissioning.

Commissioning objectives would be established largely by standards and specialized to specific projects by detailed objectives being automatically inherited by associating objectives with generic types of commissioning projects. For retro-commissioning, most activities would become a routine part of building operation and maintenance and might not require explicit development of objectives. Similarly, objectives associated with equipment startup would be unneeded because all equipment would be automatically started up and tested with standard automated start-up routines satisfying standard objectives. 
Table 1. Major Commissioning and Retro-commissioning Activities

\begin{tabular}{|c|c|}
\hline New Construction Commissioning & $\begin{array}{c}\text { Retro-commissioning Existing } \\
\text { Buildings }\end{array}$ \\
\hline $\begin{array}{l}\text { Conceptual or pre-design phase } \\
\text { a. Develop commissioning objectives }(\mathrm{A}) \\
\text { b. Hire commissioning provider }(\mathrm{M}) \\
\text { c. Develop design phase commissioning } \\
\text { requirements }(\mathrm{A}) \\
\text { d. Choose the design team }(\mathrm{M})\end{array}$ & $\begin{array}{l}\text { Planning phase } \\
\text { a. Develop commissioning objectives }(A) \\
\text { b. Hire commissioning provider }(M) \\
\text { c. Review available documentation and } \\
\text { obtain historical utility data }(A) \\
\text { d. Develop retrocommissioning plan }(A)\end{array}$ \\
\hline $\begin{array}{l}\text { 2. Design phase } \\
\text { a Commissioning review of } \\
\text { design intent }(A) \\
\text { b. Write commissioning } \\
\text { specifications for bid documents } \\
\text { (A) } \\
\text { c. Award job to contractor }(M) \\
\end{array}$ & (No design phase activities) \\
\hline $\begin{array}{l}\text { 3. Construction/installation } \\
\text { phase } \\
\text { a. Gather and review } \\
\text { documentation }(\mathrm{A}) \\
\text { b. Hold commissioning scoping } \\
\text { meeting and finalize plan }(\mathrm{M}) \\
\text { c. Develop pre-test checklists } \\
\text { (A) } \\
\text { d. Start up equipment or perform } \\
\text { pre-test checklists to ensure } \\
\text { readiness for functional testing } \\
\text { during acceptance }(\mathrm{A})\end{array}$ & $\begin{array}{l}\text { 2. Investigation phase } \\
\text { a. Perform site assessment } \\
\text { (M/A) } \\
\text { b. Obtain or develop missing } \\
\text { documentation }(A) \\
\text { c. Develop and execute } \\
\text { diagnostic monitoring and test } \\
\text { plans }(A) \\
\text { d. Develop and execute } \\
\text { functional test plans }(A) \\
\text { e. Analyze results }(A) \\
\text { f. Develop master list of } \\
\text { deficiencies and } \\
\text { improvements }(A) \\
\text { g. Recommend most cost- } \\
\text { effective improvements for } \\
\text { implementation }(A)\end{array}$ \\
\hline $\begin{array}{l}\text { 4. Acceptance phase } \\
\text { a. Execute functional tests and } \\
\text { diagnostics }(A) \\
\text { b. Fix deficiencies }(M) \\
\text { c. Retest and monitor as needed } \\
\text { (A) } \\
\text { d. Verify operator training }(A) \\
\text { e. Review O\&M manuals }(A) \\
\text { f. Building/retrofit accepted by } \\
\text { owner (M) }\end{array}$ & $\begin{array}{l}\text { 3. Implementation phase } \\
\text { a. Implement repairs and } \\
\text { improvements }(M) \\
\text { b. Retest and remonitor for } \\
\text { results }(A) \\
\text { c. Fine-tune improvements if } \\
\text { needed }(A) \\
\text { d. Revise estimated energy } \\
\text { savings calculations }(A)\end{array}$ \\
\hline $\begin{array}{l}\text { 5. Post-acceptance phase } \\
\text { a. Prepare and submit final } \\
\text { report }(M / A) \\
\text { b. Perform deferred tests (if } \\
\text { needed) }(A) \\
\text { c. Develop recommissioning } \\
\text { plan/schedule }(A)\end{array}$ & $\begin{array}{l}\text { 4. Project hand-off and } \\
\text { integration phase } \\
\text { a. Prepare and submit final } \\
\text { report }(M / A) \\
\text { b. Perform deferred tests (if } \\
\text { needed) }(A) \\
\text { c. Develop recommissioning } \\
\text { plan/schedule }(A)\end{array}$ \\
\hline
\end{tabular}

Source of original table without M and A designations: Haasl and Sharp 1999 
Commissioning plans similarly would be specified automatically based on information automatically obtained from design documents and only limited information would be input manually (e.g., special constraints on schedules). Design information would be automatically stored as developed and shared throughout the life of the building. This would include objectives and intent behind the design. Automatic storage and universal data sharing protocols would eliminate the need to manually take off information from drawings or re-input information developed in earlier phases. Ultimately, even existing buildings that were designed before automated data storage was routinely used, will possess systems that will automatically detect all aspects of the buildings, systems and equipment installed, generate the equivalent design, and evaluate it.

Designs will be automatically evaluated with respect to meeting design intents as well as energy and other standards. For many years, researchers have studied the design process and developed methods for automating both design generation and evaluation. A sampling of issues and advancements in design automation can be found in Gero 2002, Gero 2000, Caldas and Norford 2002, Iliescu et al. 2000, Fleming and Waterbury 1995, and Fleming and Aygen 2001. Research in these fields will provide the basis for automation of design review and revision performed as part of commissioning.

To the extent that commissioning specifications are still required in bid documents far in the future, most of the required language might be generated automatically, reviewed manually, and revised manually in special cases where required. Eventually, though, all documents will be reviewed automatically. Computer-based tools will parse text and "interpret" the meaning, and evaluate it with respect to needs and design criteria. Given information about the equipment and systems in a building or specified by the design, checklists (to the extent still needed) could be generated automatically. With some exceptions, most checklists would be eliminated because checks would be performed automatically. Lists might remain only as an organizational form for presenting results to human users. Just-in-time facility documentation (Song et al. 2002) may become the basis for operation and even parts of commissioning and retro-commissioning. Even proper installation of equipment (e.g., whether any fans are installed backwards) could initially be checked automatically. Some problems might require visual inspection after initial automatic detection of problems, but the labor for this would be highly targeted to problem situations.

All testing, data collection, analysis, and interpretation of results would be performed automatically. Examples of how some tests could be executed automatically today are given by Katipamula et al. 2003, PECI and Battelle 2003, and Brambley and Katipamula 2003. These capabilities are based on research and development in the fields of automated fault detection, diagnostics and prognostics. "Fixing deficiencies" and "implementing repairs and improvements" are designated in Table 1 as being done manually; however, only repairs and improvements requiring physical repair, replacement, or reinstallation require human intervention. As shown in PECI and Battelle 2003 and Katipamula et al. 2003, some repairs such as revising control code, changing set points, and recalibrating sensors might be done automatically with no human 
intervention except to read a short report from the computerized system regarding actions it took. Automatically retuning of control algorithms is also possible today for some applications and most tuning will be done automatically in the long-term future.

As indicated in Table 1, most commissioning activities will be done automatically at some time in the future. People will still need to coordinate the processes and ensure that reporting to owners and management is appropriate, but many of the commissioning activities executed manually today will become automatic. This transformation will reduce the labor, time, and cost of commissioning and help overcome some of the key barriers that widespread application of commissioning faces today. Reaching that future, however, will require advances in key enabling technologies and then application of them to building systems. Table 2 provides a list of key technologies needed to achieve this future and the capabilities for commissioning that each might provide. 
Table 2. Technologies Needed for Highly Automated Commissioning

\begin{tabular}{|c|c|}
\hline Technology & Potential Applications \\
\hline $\begin{array}{l}\text { Wireless sensing, data acquisition, } \\
\text { and control }\end{array}$ & $\begin{array}{l}\text { Cost effective sensing and data } \\
\text { collection } \\
\text { Condition monitoring }\end{array}$ \\
\hline $\begin{array}{l}\text { Plug and play building equipment and } \\
\text { controls }\end{array}$ & $\begin{array}{l}\text { Self-identifying equipment and } \\
\text { automatic system design } \\
\text { recognition } \\
\text { Rapid automatic self-configuration } \\
\text { of controls } \\
\text { Automatic control algorithm } \\
\text { selection and application }\end{array}$ \\
\hline $\begin{array}{l}\text { Embedded networked sensing and } \\
\text { processing }\end{array}$ & $\begin{array}{l}\text { Highly distributed processing of } \\
\text { information with local control } \\
\text { capabilities coordinated to meet } \\
\text { system and building level } \\
\text { objectives }\end{array}$ \\
\hline $\begin{array}{l}\text { Automated fault detection, } \\
\text { diagnostics, and prognostics }\end{array}$ & $\begin{array}{l}\text { Automatic detection and diagnosis } \\
\text { of operation, equipment, and } \\
\text { control faults } \\
\text { Automatic detection and diagnosis } \\
\text { of designs and hardware } \\
\text { installations } \\
\text { Anticipation of system and } \\
\text { equipment degradation based on } \\
\text { condition monitoring } \\
\text { Automatic generation of } \\
\text { maintenance plans } \\
\text { Condition-based maintenance }\end{array}$ \\
\hline Automated proactive testing & $\begin{array}{l}\text { Automated startup and functional } \\
\text { tests, analysis of data, and } \\
\text { interpretation of results } \\
\text { Continual automated monitoring } \\
\text { and testing }\end{array}$ \\
\hline $\begin{array}{l}\text { Automatic records management and } \\
\text { data exchange protocols }\end{array}$ & $\begin{array}{l}\text { Automatic generation of plans and } \\
\text { reports } \\
\text { Automatic storage of data } \\
\text { Automated asset tracking } \\
\text { Automatic project management } \\
\text { assistance }\end{array}$ \\
\hline
\end{tabular}

Wireless data communication will eliminate many of the wires required today to collect data or transmit control signals to device actuators. Wires can represent a significant fraction of the cost of a sensor or control point. As a result, wireless communication for sensors and controls will enable more ubiquitous use of sensing, increasing information on the operating state of systems and equipment available at any point in time and enabling better control and maintenance. Plug and play controls and equipment will enable quicker installation and set up of physical systems and controls. Controls will ultimately become self-writing, given some input on the performance objectives for the building and equipment characteristics. Small, embedded, networked processors will distribute control to a greater degree than today's control systems, leading to better, 
higher resolution, system response while coordinating through networking with other subsystems and components to achieve building-level objectives.

Automated fault detection and diagnostics will lead to greater awareness of system conditions throughout buildings on a continuous basis (see Figure 1). Corrective actions will be enacted automatically by "aware" agents capable of correcting faults in some cases (e.g., correcting a control schedule or fixing an incorrect set point). In cases where automatic fault correction is not possible, notifications will be provided to building staff and management regarding faults and their costs. No longer will faults go unrecognized or will an engineer need to study data patterns to detect them. The operating state of building systems will be known along with the performance and cost impacts of problems so priorities for operation and maintenance can be made with complete information. Prognostic techniques will automatically predict the remaining serviceable life of equipment and suggest condition-based maintenance actions. Automated proactive testing will be the basis for short-term functional testing. These tests allow a wide range of conditions to be simulated over a relatively short period of time so that problems can be detected faster than if only passive observation of routine operation is used. Proactive testing will enable consistent performance of functional tests automatically during initial commissioning and then at regular periods throughout the life of the building.

Fault detection and diagnostic methods will have applications in design review in addition to use on physical components. Diagnosis of design is similar to diagnosis of a physical device. First a problem or fault is detected with the design. Evaluation of the design indicates that it does not satisfy some design criterion (requirement). This is analogous to fault detection. Then the reason for the fault existing (its cause) is identified or isolated, which is analogous to fault diagnosis or isolation. The design then needs to be revised to correct the deficiency, which parallels fault correction. When this entire process is automated, it will provide continuous review and evaluation of designs as they evolve. This will likely be done by automated agents (processes whose purpose is to execute part of the design review and report the results), each of which is responsible for evaluation with respect to a small subdomain. Some of these agents will specifically handle evaluations from the perspectives of commissioning.

Data exchange protocols will provide the basis for sharing data among automated agents as well as commissioning professionals, operating staff, and facility management. Radio frequency identification tags will also play a role in tracking assets as well as enabling easy, automatic identification of each piece of equipment and component, enabling automatic checking for consistency with specifications as equipment arrives on the construction site, and assessing its installation. Tags may also provide physical and performance characteristics from manufacturer tests, which then will become available to processes that evaluate the correctness of installation, develop control algorithms, evaluate functional test results, and monitor performance. Geographic information systems (GIS) as well as localization algorithms using wireless communications information (see, for example, Savvides et al. 2004) will be used to determine locations of equipment. Together these technologies will enable realization of highly automated commissioning and operation. 


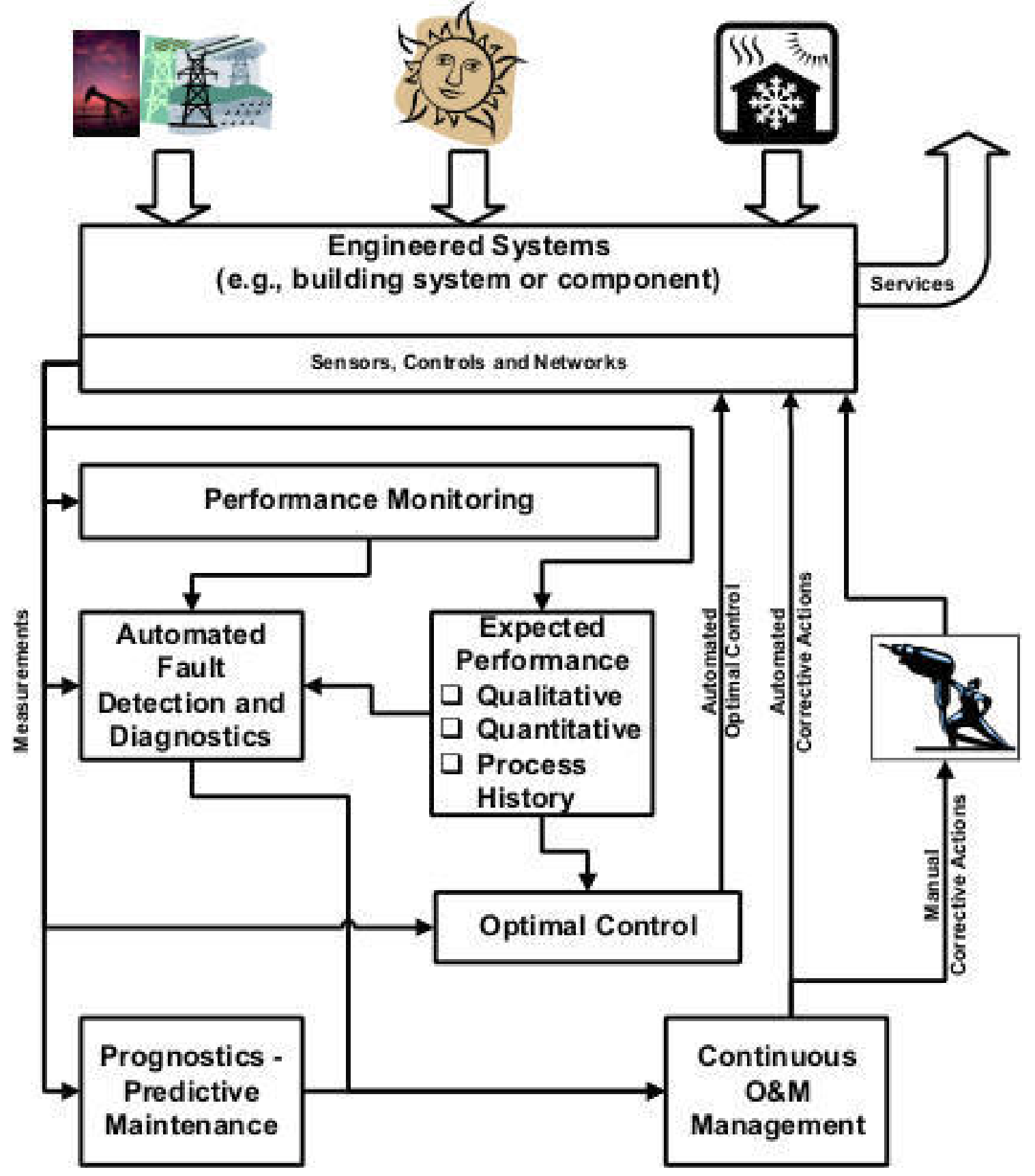

Figure 1. Advanced automated retro-commissioning process.

\section{The Path To This Future}

The impediments to realizing a future where building commissioning and retrocommissioning are largely automated are both technological, social and institutional. Without the technology, however, the vision is not possible. With it, automated capabilities for executing all but the management, repair, and replacement activities of retro-commissioning could be delivered as parts of equipment packages and control 
systems. With the addition of design tools, this could be extended to commissioning of new buildings. Advances in each of the technologies identified in Table 2 will be needed.

Because the buildings industries are highly fragmented, public R\&D organizations will need to provide leadership to produce this technology. Even then, a market demand will need to develop to drive the creation of new equipment and control systems with automated commissioning capabilities. The building commissioning industry will evolve, gaining market share over time as energy and electric power prices increase and more burden for management of the electric power grid is pushed to end users (see, for example, http://gridwise.pnl.gov/ for a vision of the future electric power grid in which "customers" play an active role). Penetrating the market will require improved cost effectiveness for commissioning, as well as education of building owners and operators regarding the benefits of commissioning. Commissioning will need to change in ways that reduce cost while preserving or even enhancing the returns on it. The practice of commissioning will likely change gradually over time with the introduction of new tools that automate parts of the process.

Market transformation programs at the federal, regional, state and local levels can help spread the application of commissioning for the public good. Research, development, deployment and market transformation programs will be needed to accelerate the introduction of automated capabilities and the spread of commissioning, improving the performance of the building stock and bringing energy and environmental benefits. Still, the willingness of the commissioning profession to accept and embrace these technologies will be critical to determining their rate of penetration. Resistance won't stop the introduction of the technologies, only delay their application, but earlier acceptance will help accelerate capture of the benefits associated with high-quality, widespread commissioning even if the mechanism of delivery changes.

\section{Conclusions - A Call to Arms}

Automation could change the nature of the commissioning process for both new and existing buildings. The services performed today as part of commissioning of existing buildings should become part of routine operation and maintenance with automated monitoring, testing, and diagnosis continually performed by the building systems and equipment themselves, taking much of the responsibility off humans.

Still, repairs and replacement of hardware will continue to require human intervention. Deteriorating bearings in pumps, failed windings in fan motors, and leaking valves will need humans to

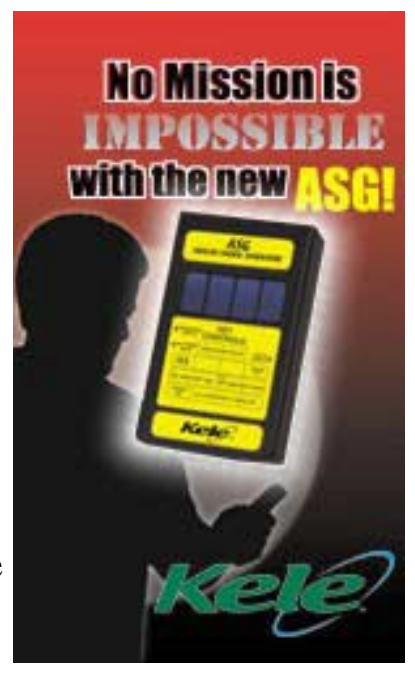
repair or replace them. Automation can only prompt repair technicians to take action to make repairs. Likewise, equipment found to be installed incorrectly during construction (e.g., a fan installed backwards) would require human involvement to remove and 
reinstall it properly. For the commissioning cycle to be complete, humans will still need to respond to information provided automatically.

The services provided by commissioning during design and construction should become integral parts of those phases of the building life cycle. Assurance of their proper consideration during these phases of building projects may still require an advocate, like the commissioning agent today, but ideally these responsibilities will be taken over by other members of design and construction teams. In any case, the provider of these services is likely to focus on design and construction, rather than responsibilities over the entire building life cycle.

System start up, like commissioning responsibilities during operation, is likely to become increasingly automated. Equipment and systems should become self-configuring, selftesting, and self-verifying. Even proper installation is likely to be automatically verified. Once again, though, when equipment and system components are found to be installed incorrectly, human technicians will still need to take responsibility to repair the installation. Equipment though may become intolerant to problems it detects (fail safe), refusing to start up until all problems it detects with the installation are corrected.

Automation will likely change the role of commissioning over time and in 20 or 30 years, its objectives may be met completely differently than they are today. These changes will not occur overnight but rather over many years, but they should lead to more cost effective delivery of the outcomes promoted by commissioning to a much broader segment of the commercial buildings market. Change is inevitable and will bring benefits. As with use of automation in design, detractors will find problems with greater use of automation in commissioning; proponents will grasp increased automation as an opportunity (Chastain 2002). The authors recommend that the building commissioning community embrace the opportunities posed by new technology and employ them to deliver better services.

Research and development will be required to achieve the benefits of greater automation in commissioning but so will adoption by the various players in the commissioning and broader buildings communities. Researchers and providers of services alike have the opportunity to transform the delivery of commissioning's objectives by working in concert to pursue a vision in which those objectives are delivered faster, less expensively, more thoroughly, more consistently, more reliably, more cost effectively, and more continuously, to a broader market through automation.

\section{References}

Brambley, M. R. and S. Katipamula. 2004. "Beyond Commissioning." In Breaking Out of the Box,

Proceedings of the 2004 ACEEE Summer Study on Energy Efficiency in Buildings. Washington, DC: American Council for an Energy Efficient Economy. 
Brambley, M. R. and S. Katipamula. 2003. "Automating Commissioning Activities: Update with Examples."

In Proceedings of the 11th National Conference on Building Commissioning, May 20-22, 2003.

Portland, Ore.: Portland Energy Conservation Inc.

Caldas, L. G. and L. K. Norford. 2002. "A Design Optimization Tool Based on a Genetic Algorithm." Automation in Construction 11(2):173-184.

Chastain, T., Y. E. Kalay and C. Peri. 2002. "Square Peg in a Round Hole or Horseless Carriage?

Reflections on the Use of Computing in Architecture." Automation in Construction 11(2):237-248.

Claridge, David E, Charles H. Culp, Mengsheng Liu, S. Deng, Wayne D. Turner, and Jeffery S. Haberl. 2000.

"Campus-Wide Continuous Commissioning ${ }^{\mathrm{SM}}$ of University Buildings." In

Proceedings of the 2000

ACEEE Summer Study. Washington, D.C.: American Council for an Energy

Efficient Economy.

Fleming, U. and Z. Aygen. 2001. "A Hybrid Representation of Architectural Precedents." Automation in Construction 10(6):687-699.

Fleming, U. and R. Waterbury. 1995. "Software Environment to Support Early Phases in Building Design (SEED):

Overview." Journal of Architectural Engineering 1(4):147-152.

Friedman, H. and M. A. Piette. 2001. Comparative Guide to Emerging Diagnostic Tools for Large Commercial

HVAC Systems. LBNL 48629. Berkeley, Ca.: Lawrence Berkeley National Laboratory.

Available online: http://www.peci.org/library/PECI_DxToolsGuide1_1002.pdf.

Gero, J. S. 2000. "Developments in Computer-Aided Design," in INCITE 2000, H. Li, Q. Shen, D. Scott and P. Love (eds.), pp. 16-24. Hung Hom, Kowloon, Hong Kong: HKPU Press.

Gero, J. S. 2002. “Advances in IT for Building Design,” In Advances in Building Technology,

M. Anson, J. Ko and E. Lam (eds.), pp. 47-54. Amsterdam: Elsevier.

Haasl, T. and T. Sharp. 1999. A Practical Guide for Commissioning Existing Building., Portland, Ore.: Portland

Energy Conservation Inc. and Oak Ridge, Tenn.: Oak Ridge National Laboratory. 
Iliescu, S., P. Fazio and K. Gowri. 2000. "Similarity Assessment in a Case-Based

Reasoning Framework

for Building Envelope Design.” In INCITE 2000, H. Li, Q. Shen, D. Scott and P.

Love (eds.), pp. 697-713.

Hung Hom, Kowloon, Hong Kong: HKPU Press.

Katipamula, S. and M. R. Brambley. 2005. "Methods for Fault Detection, Diagnostics and Prognostics for

Building Systems - A Review." Accepted for publication in 2005 by the

International Journal of Heating,

Ventilating, Air-Conditioning and Refrigerating Research.

Katipamula, S., M. R. Brambley, and L. Luskay. 2003. "Automated Proactive Techniques for Commissioning Air-Handling Units."

ASME Journal of Solar Energy Engineering, Transactions of the ASME, Special Issue on Emerging Trends in Building Design,

Diagnosis and Operation 125(1):282-291.

Liu, M., D. E. Claridge, and W. D. Turner. 2002. "Continuous Commissioning ${ }^{\text {SM }}$ Guide Book."

Washington, D.C.: Federal Energy Management Program, U.S. Department of Energy.

Available on the worldwide web at:

http://www.eere.energy.gov/femp/pdfs/ccg01_covers.pdf.

Mills, E., H. Friedman, T. Powell, N. Bourassa, D. Claridge, T. Haasl, and M. A. Piette. 2004.

The Cost-Effectiveness of Commercial Buildings Commissioning - A Meta-Analysis of Existing Buildings and

New Construction in the United States. LBNL-56637. Berkeley, Calif.: Lawrence

Berkeley National Laboratory.

Available online: http://eetd.lbl.gov/emills/PUBS/CX-Costs-Benefits.html.

Portland Energy Conservation, Inc. (PECI) and Battelle Northwest Division. 2003.

Methods for Automated and Continuous

Commissioning of Building Systems. Final Report. ARTI-21CR/610-30040-01. Air-

Conditioning \& Refrigeration Technology

Institute, Washington, D.C. Available online: www.arti-

21cr.org/research/completed/finalreports/30040-final.pdf.

Quantum Consulting. 2003. Market Progress Evaluation Report--Commissioning In Public Buildings Project, $\quad$ No. Report \#E03-107. Portland, Ore.: Northwest Energy Efficiency Alliance. Available online:http://www.nwalliance.org/resources/reports/107.pdf. 
Savvides, A., M. Srivastava, L. Girod, and D. Estrin. 2004. Chapter 15 in Wireless Sensor Networks,

C. S. Raghavendra, K. M. Sivalingam and T. Znati (eds.), pp. 327-349. Boston, Mass.: Kluwer Academic Publishers.

Song, Y., M. J. Clayton, and R. E. Johnson. 2002. “Anticipating Reuse: Documenting Buildings for Operations

Using Web Technology." Automation in Construction 11(2):185-197.

U.S. DOE. Undated. Building Commissioning - The Key to Quality Assurance. Washington, D.C.: U.S. Department of Energy, Rebuild America Program. Available online:

http://www.rebuild.org/attachments/guidebooks/commissioningguide.pdf.

${ }^{[1]}$ An earlier version of this paper was presented at the 2004 ACEEE Summer Study on the Energy Efficiency of Buildings and is published in the proceedings of that conference (Brambley and Katipamula 2004).

${ }^{[2]}$ Operated by Battelle Memorial Institute for the U.S. Department of Energy.

[3] Throughout this paper, the authors use the term "commissioning" to represent generically all forms of the process applied to both new buildings during design and construction and existing buildings already in operation, as well as the specific process for new construction. The context establishes which use is intended.

${ }^{[4]}$ A comprehensive review of fault detection, diagnostic, and prognostic methods can be found in Katipamula and Brambley 2005, and a recent review of tools using such methods is provided by Friedman and Piette 2001 (http://www.peci.org/library/PECl DxToolsGuide1 1002.pdf). 


\section{Some Related Automated Buildings Links:}

A Wake-Up Call and a Brainer Ask any economist worth his salt what the total impact on American industry would be if our gross use of energy were to decrease by $15 \%$ over the next 10 years.

Waking Up to Wireless Wireless.... WAKE UP it is here and it is now!

Wireless Mesh Sensor Networks Enable Building Owners, Managers, and Contractors to Easily Monitor HVAC Performance Issues

If Buildings Were Built Like Cars The Potential for Information and Control Systems Technology in New Buildings

Autonomic Wireless Building Networks The key to reliable ad hoc

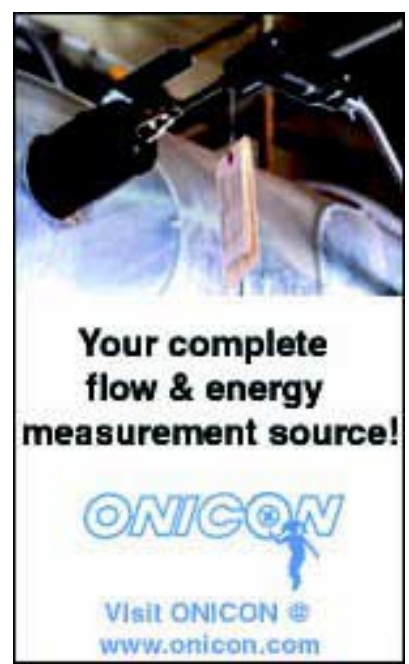

wireless networking for building automation applications and protocols is an Autonomic mesh network: an Autonomic network is one that self-configures, self-heals, self-regulates, and understands when to apply these parameters.

\section{Reaping the Benefits of IP How IP Access Technology is Making 'Intelligent Buildings' a Reality}

Ending the Blackout Blues We need (REALLY need) to improve the way our industry delivers more advanced technologies to our building construction projects

"IT" Could be the Start of Something Big Now, with the growing use of building networks and the convergence of building controls and IT networks, it is becoming far easier to connect building occupants to the building control system by employing a simple "comfort and lighting" icon on each occupant's PC.

Web-Based Automation Access to real-time information anywhere, anytime through an Internetenabled automation system is the real value of this technology.

\section{A "Black Box" ...what Building Automation needs!}

Web-Based Control Systems - Doing more with more More access, more flexibility, more interoperability, wider area integration, but not more cost.

Web Based Facilities Operations Guide Doing more with less by using Web-based anywhere information to amplify your existing building operational resources.

Building Systems Commissioning: Let Technology do the Heavy Lifting Having the control network installed early in the construction phase allows the building automation system to do as much of the heavy lifting as possible including centralized data collection, analysis and reporting.

Tools for Commissioning and Building Tune Ups The importance of building commissioning and tune-ups has recently taken center stage. 